\title{
EDITORIAL
}

\section{Pediatric Barrett's Esophagus: A Fifth Column?}

\author{
Maximilien Barret ${ }^{1}$
}

Accepted: 26 August 2020 / Published online: 18 September 2020

(c) Springer Science+Business Media, LLC, part of Springer Nature 2020

Barrett's esophagus (BE) is the primary risk factor for esophageal adenocarcinoma, increasing the risk of developing the disease over tenfold. BE is defined by the British Society of Gastroenterology by the presence of a salmoncolored mucosa in the tubular esophagus extending at least $1 \mathrm{~cm}$ above the gastroesophageal junction with histologically confirmed metaplastic columnar epithelium [1], whereas in contrast, the American College of Gastroenterology guidelines and European Society of Gastrointestinal Endoscopy position statement require the presence of intestinal metaplasia (columnar epithelium with goblet cells) in order to confirm the diagnosis of BE [2, 3]. Indeed, the neoplastic potential of esophageal intestinal metaplasia is 5 times higher than that of cardiac or fundic-type columnar metaplasia [4], the two other subtypes of columnar metaplasia in the esophagus, reaching an annual risk of adenocarcinoma of $0.2-0.5 \%$ [2]. In this context, the basis of the management of BE is endoscopic and histologic surveillance every 3-5 years, depending on the length of the BE segment ( $\geq 3 \mathrm{~cm}$ or $<3 \mathrm{~cm}$, respectively), with endoscopic resection of all visible abnormalities and more aggressive treatment for ablation and removal of confirmed dysplastic BE.

While gastroesophageal reflux is physiological during the first year of life due to immaturity of the lower esophageal sphincter, gastroesophageal reflux disease (GERD) occurs in up to $10 \%$ of children [5] and may persist into adulthood in a third to half of these patients [6, 7]. Nevertheless, the consequences of childhood GERD, and particularly BE, have been scarcely studied.

In this issue of Digestive Diseases and Sciences, TwohigBennett et al. (following the British guidelines) report on the epidemiology of esophageal columnar metaplasia in children in a population-based case series analysis from the Northern Ireland BE register [8]. Over an 18-year timeframe, 13,336

Maximilien Barret

maximilien.barret@aphp.fr

1 Department of Gastroenterology and Digestive Oncology, Cochin Hospital and University of Paris, 27, Rue du

Faubourg St Jaques, 74014 Paris, France incident cases of BE were recorded, among which 42 were in children, with a mean age of 10 years and an $86 \%$ proportion of males. This pediatric group accounted for $0.3 \%$ of all $\mathrm{BE}$ cases, corresponding to an age-adjusted incidence of $<2 / 100,000$ children. Importantly, while all 42 children had columnar metaplasia, none had intestinal metaplasia at initial diagnosis and none developed dysplasia or esophageal adenocarcinoma before age 16. Further, though 33 children had no follow-up endoscopy and biopsy, nine children did, of whom six developed intestinal metaplasia as adults; and furthermore, four ultimately developed low-grade dysplasia in early adulthood (22-24 years old).

Although limited by the small proportion of patients with long term biopsy and endoscopic follow-up data, this work describes the largest cohort of pediatric patients with esophageal columnar metaplasia, and facilitates comparison with a large number of adult patients from the North Ireland $\mathrm{BE}$ register. As is the vast majority of published work on the epidemiology of $\mathrm{BE}$, since the paper actually reports the caseload of children with BE (i.e., the number of children receiving medical care) rather than the prevalence of $\mathrm{BE}$ in children (i.e., the proportion of children with BE in the children population), the actual prevalence of esophageal columnar metaplasia in children is likely to be higher. This could be a concern, since the duration of $\mathrm{BE}$ and the presence of dysplasia are the major risk factors for neoplastic progression. The conclusions that can be drawn from this work are straightforward and could impact clinical practice, especially given that the Twohig-Bennett et al. manuscript concurs with the limited evidence that already is available on this topic $[9,10]$. Noteworthy is that the children in the Twohig-Bennett paper do not actually have BE as defined by the presence of intestinal metaplasia by European and American guidelines, and so have virtually no neoplastic potential during childhood. Therefore, one can conclude that surveillance endoscopies for esophageal columnar metaplasia in children under 16 years old can be avoided. Nonetheless, since the manuscript also shows that cardiac type and fundic metaplasia may represent immature forms of BE that 
can evolve to intestinal metaplasia and (low-grade) dysplasia, endoscopic surveillance can be justified as they reach young adulthood.

Funding None.

\section{Compliance with Ethical Standards}

Conflict of interest Medtronic: fees for teaching and medical training; Norgine: board participation.

\section{References}

1. Fitzgerald RC, di Pietro M, Ragunath K, et al. British Society of Gastroenterology guidelines on the diagnosis and management of Barrett's oesophagus. Gut. 2014;63:7-42.

2. Shaheen NJ, Falk GW, Iyer PG, Gerson LB. American College of Gastroenterology: ACG Clinical Guideline-diagnosis and management of Barrett's Esophagus. Am J Gastroenterol. 2016;111:30-50.

3. Weusten B, Bisschops R, Coron E, et al. Endoscopic management of Barrett's esophagus: European Society of
Gastrointestinal Endoscopy (ESGE) position statement. Endoscopy. 2017;49:191-198.

4. Bhat S, Coleman HG, Yousef F, et al. Risk of malignant progression in Barrett's esophagus patients: results from a large population-based study. J Natl Cancer Inst. 2011;103:1049-1057.

5. Singendonk M, Goudswaard E, Langendam M, et al. Prevalence of gastroesophageal reflux disease symptoms in infants and children: a systematic review. J Pediatr Gastroenterol Nutr. 2019;68:811-817.

6. Johnston BT, Carré IJ, Thomas PS, Collins BJ. Twenty to 40 year follow up of infantile hiatal hernia. Gut. 1995;36:809-812.

7. El-Serag HB, Sweet S, Winchester CC, Dent J. Update on the epidemiology of gastro-oesophageal reflux disease: a systematic review. Gut. 2014;63:871-880.

8. Twohig-Bennett L, Coleman HG, Cairnduff V, et al. Esophageal columnar metaplasia in childhood: A population-based case series analysis. Dig Dis Sci (Epub ahead of print). https://doi. org/10.1007/s10620-020-06462-5.

9. Raicevic M, Saxena AK. Barrett's esophagus in children: what is the evidence? World J Pediatr. 2018;14:330-334.

10. Putra J, Arva NC, Tan SY, et al. Barrett esophagus and intestinal metaplasia of the gastroesophageal junction in children: a clinicopathologic study. J Pediatr Gastroenterol Nutr. 2020;70:562-567.

Publisher's Note Springer Nature remains neutral with regard to jurisdictional claims in published maps and institutional affiliations. 